\title{
Conflictos socio-ambientales en la sociedad moderna: aportes de la ecología política Latinoamericana y la teoría de la acción comunicativa
}

\author{
Felipe Cárcamo $^{\text {a } 1}$ \\ Rodrigo Mena ${ }^{\text {a,b }}$ \\ a Universidad Central La Serena, Chile \\ b Erasmus University Rotterdam, The Netherlands
}

\begin{abstract}
Modern society's socio-environmental conflicts result from multiple causes, and responding to them is a complex, multidisciplinary venture. This article contributes to the understanding of that complexity, with a discussion of the main analytical keys that political ecology has used for the study of socio-environmental conflicts in Latin America. The article shows the important role that communication takes in this process, and argues that the Theory of Communicative Action can contribute to the political ecological analysis of socio-environmental conflicts in modern society, and can identify paths that allow the establishment of new alternative projects.
\end{abstract}

Palabras clave: Socio-environmental conflicts, political ecology, Latin America, communicative action, modern society, alternative projects

\section{Résumé}

Les conflits sociaux-environnementaux marquant nos sociétés modernes résultent de causes multiples. Répondre à ces conflits nécessite non seulement une approche complexe, mais aussi multidisciplinaire. Souhaitant contribuer à la compréhension de cette complexité, cet article se base sur un projet de recherche exploratoire afin d'appliquer les outils analytiques de l'écologie politique aux conflits sociauxenvironnementaux en Amérique du Sud. Développant le rôle joué par la communication dans ce procédé, notre analyse expérimente avec des éléments de la théorie d'action communicative, enrichissant ainsi l'analyse de conflits sociaux-environnementaux par le prisme de l'écologie politique. Ceci implique une réflexion sur nos sociétés modernes, et l'examen critique de trajectoires menant à la mise en place de nouveaux projets alternatifs.

Mots clés: Conflits sociaux-environmentaux, écologie politique, Amérique Latine, ecologie, action communicative, société modern, projets alternatifs

\section{Resumen}

Los conflictos socio-ambientales presentes en la sociedad moderna actual responden a múltiples causas y su abordaje es a la vez complejo y multidisciplinar. El presente artículo, buscando aportar al entendimiento de esa complejidad, desarrolló una investigación exploratoria para conocer las principales claves analíticas que la Ecología Política ha entregado al abordaje y comprensión de los conflictos socio-ambientales en Latinoamérica. Profundizando en el rol que la comunicación asume en este proceso, un segundo análisis exploró elementos de la Teoría de la Acción Comunicativa que podrían aportar a la lectura de los conflictos socio-ambientales y el estudio de los mismos por la Ecología Política. Lo anterior, específicamente desde la crítica a la sociedad moderna, examinando salidas reales que permitan posicionar y conquistar nuevos proyectos alternativos.

Palabras clave: Conflictos socio-ambientales, ecología política, América Latina, acción comunicativa, sociedad moderna, proyectos alternativos

\footnotetext{
${ }^{1}$ Felipe Cárcamo, Investigador en Centro de Estudios Culturales Aplicados en Puerto Montt, Sociólogo, Universidad Central, La Serena, Chile. Email: f.carcamo.moreno "at" gmail.com. Rodrigo Mena, Académico Asociado de la Universidad Central de Chile y PhD student, International Institute of Social Studies (ISS), Erasmus University Rotterdam, The Hague, The Netherlands. Email: mena "at" iss.nl. Los autores desean agradecer a los editores de la JPE, Simon Batterbury y Casey Walsh, y a los revisores anónimos por su orientación y retroalimentación.
} 


\section{Introducción}

Muchos problemas o conflictos ambientales que suceden en la actualidad, tanto a nivel local como global, suelen ser complejos y difíciles de abordar. Plantean problemáticas no abordables unidisciplinariamente por la biología, ecología o climatología, por nombrar algunas, ya que su naturaleza es de carácter multi-causal, atravesados por dimensiones sociales, políticas, económicas, culturales y/o ecológicas (Hannigan 2006). La ecología política se ha destacado por brindar al estudio de estos conflictos una mirada más social y política, ampliando así el campo y métodos de estudio de las problemáticas ambientales. Buscando desentrañar este aporte de la ecología política, se diseñó una investigación que permitiera lograr tres objetivos principales: Explorar la multiplicidad de temas que una mirada política ecología provee al estudio de conflictos ambientales, entregue claves de análisis que aporten al estudio interdisciplinar de los conflictos ambientales, y permitiera fortalecer o explorar nuevas maneras de abordar problemáticas ambientales.

Para lograr lo anterior se decidió utilizar Latinoamérica como caso de estudio. La decisión de focalizar el estudio en Latinoamérica se sustenta, primero, en que se buscó un caso de estudio que presentará una historia relevante de conflictos ambientales a la vez que cuente con un cuerpo relevante de literatura desde la ecología política sobre esos conflictos. Junto a lo anterior, se eligió un caso (región) que fuera asequible a los investigadores en término de fuentes de información, idioma de la misma e informantes claves. Considerando estas variables, Latinoamérica se presenta como un caso de estudio típico, según la definición entregada por Gerring (2007), aun reconociendo la diversidad que la región supone dentro de sí misma. También se acepta que este estudio no es representativo de la realidad de todos los países que componen la región, y la validez del estudio es interna y de constructo, por sobre externa y representativa (Gerring 2007; Yin 2009). Finalmente, el presente estudio no busca reconstruir un mapa de todo lo escrito bajo la etiqueta de ecología política en o sobre América Latina, pero si tras un estudio exhaustivo, reconocer claves de relevancia.

El aporte de desarrollar lo anterior permite no sólo fortalecer la relevancia de la mirada política ecológica, pero además y de manera innovadora observar cuáles han sido los principales temas que la ecología política ha abordado en Latinoamérica. Los resultados de esta primera parte de la investigación dieron cuenta que en la mayoría de los análisis políticos ecológicos de los conflictos socio-ambientales, el estudio de los procesos comunicativos de los mismos es central. Utilizando este resultado como cimiento, se desarrollaron los objetivos de reflexionar sobre nuevas claves de análisis (en este caso lo comunicativo) y cómo éstas pueden ser integradas al abordaje político ecológico de los conflictos socio-ambientales. Para lograr lo anterior se utilizó la Teoría de la Acción Comunicativa de Jürgen Habermas, en especial los términos de acción instrumental y acción comunicativa. Como se desarrollará más adelante, tras la exploración de la teoría de la comunicación, estos conceptos y su marco teórico resultaron ser útiles y con el potencial de aportar al abordaje político ecológico de los conflictos socio-ambientales.

Creemos necesario dar cuenta que la presente investigación informa desde lo que se ha escrito y publicado sobre la ecología política (en adelante EP) y ciertamente no refleja todo lo que hace, presenta, y discute. Se ha encontrado (y hemos participado) en una multitud de congresos o seminarios sobre EP donde múltiples temáticas son abordadas y discutidas, muchas veces dando cuenta de la cantidad de proyectos o actividades sociales y públicas que se desarrollan con un explícito enfoque político-ecológico. De modo similar, existen diversos blogs, páginas web y espacios de discusión que declaran suscribir a la EP, donde diversas temáticas abordadas dan cuenta no sólo de la riqueza de la EP en la región, sino también fortaleciendo su carácter social, práctico y de discusión crítica en torno a los conflictos socio-ambientales, más allá de su empresa académica. Sin duda, futuras investigaciones sobre lo que se presenta y propone en estas esferas sería de gran aporte y relevancia para la EP. Por ahora el foco estuvo en las empresas de difusión escrita y académica mediante libros y artículos en revistas con revisión de pares.

Como técnica de análisis de la información, se desarrolló un análisis temático usando las seis fases propuestas por Braun y Clarke (2006, en Mieles, Tonon y Alvarado 2012):

1) Familiarización con los datos;

2) Generación de códigos iniciales;

3) Búsqueda de temas;

4) Revisión de temas;

5) Definición y denominación de temas; y la

6) Redacción del informe final. 
En cuanto a las técnicas de recolección, se desarrolló una revisión bibliográfica de estudios y marcos teóricos políticos ecológicos en la región.

El siguiente capítulo describe de manera amplia qué se entiende por conflicto socio-ambiental y la complejidad de estos. Acto seguido, se presentan los resultados sobre principales temáticas de la Ecología Política Latinoamericana. El cuarto capítulo aborda la dimensión comunicativa de la EP, la decisión de explorar la Teoría de la Acción Comunicativa y las claves que ésta provee para el estudio de los conflictos socio-ambientales. Un capítulo final presenta un proceso reflexivo de la información entregada, para dar paso a conclusiones generales.

\section{Ecología Política, conflictos socioambientales y Latinoamérica}

Como presentará Blaikie (1995), lo ambiental es socialmente construido y, por lo tanto, se hace difícil hablar de problemáticas o conflictos puramente ambientales. Sin embargo, no todo problema social es además ambiental, y no todo problema ambiental forma un conflicto. Un problema social se entiende generalmente como "una situación argüida que es incompatible con los valores de un número significativo de personas, que coinciden en que se necesita una acción para alterar la situación" (traducido por los autores de Rubington and Weinberg 2003: 4). Por otra parte, conflicto es un concepto amplio, que se refiere a la competencia, choque o contradicción entre dos o más grupos sociales, actores o grupos sobre un objetivo, recurso o interés específico (Estévez et al. 2015; Galtung 1996; Homer-Dixon 1994; Oberschall 1978). En otras palabras, un conflicto alude a una dinámica de oposición, controversia, disputa o protesta de actores (Walter 2009). También como columna vertebral de un conflicto social a diferencia de un problema social, es la presencia de un conjunto relevante individuos, con una preocupación colectiva y compartida (Galtung 1996; Oberschall 1978).

Los problemas o conflictos ambientales, como trataría Bell (2012) y Hannigan (2006), comparten el hecho de ser situaciones de afectación ecológica pero que son tematizados, operacionalizados y entendidos como problemas o conflictos sociales. Es por lo tanto posible denominarlos problemas socioambientales, para enfatizar su condición multidisciplinar.

Como todo problema social, los conflictos y problemas socio-ambientales presentan múltiples formas de ser abordados, siendo extraño encontrar una única forma correcta (Bardwell 1991). Hacer frente a estos problemas supone (a) superar la solución técnica para avanzar a aquellas reflexivas, multidisciplinares y críticas (Bardwell 1991; Bordehore 2001; Hannigan 1995), como también (b) pensar en los actores, instituciones, grupos y los marcos normativos y/o culturales donde se desarrollan (Alonso and Costa 2002; Campos and Larenas 2012; Krüger 2015; Walter 2009). En palabras de algunos autores, en los agentes, su agencia y estructuras (Berger and Luckmann 1990; Bourdieu 2007 2011; Giddens 1995; Parsons 1968).

Para Enrique Leff (2010) la crisis ambiental actual convoca la necesidad de pensar en un sujeto que sea ecológico con las cualidades suficientes para poder responder al ambientalismo complejo y multifacético, que por sobre lo anterior, se manifiesta en un campo de múltiples intereses, relaciones, y acciones que disputan los sentidos e interpretaciones de la naturaleza. Más aún, estos problemas han servido como articuladores de actores sociales antes dispersos, ahora organizados en torno a una temática única, a la vez diversa, pero que es acorde a una perspectiva actualizada, conformada por múltiples identidades, complejo, y fluido, que pretende incorporar intereses, derechos comunes e identidades colectivas (Barca 2015; Leff 2001).

A pesar de la complejidad que puede suponer abordar estos conflictos socio-ambientales, existen empresas académicas que abordan la temática y entregan claves de lecturas relevantes para su abordaje. Dentro de estas empresas, la ecología política ha resaltado como campo de estudio y revelamiento de estos conflictos. Al igual que en otras regiones, en Latinoamérica la EP ha sido abordada por diferentes autores y es un cuerpo amplio de pensamiento, abordando una multiplicidad de tópicos y por tanto, con una columna vertebral difusa (Batterbury 2004; Neumann 2005; Zimmerer and Bassett 2003). Un elemento común es el entendimiento de la misma como un campo que está en constante construcción y que tiene sus raíces en la catástrofe de la conquista, resistencias anticolonialistas y antiimperialistas, bajo la integración en posición subordinada al sistema internacional (Martínez-Alier 2011a).

Más aún, la EP no sólo se queda en su rol revelador y crítico, no es sólo un hacha que busca cortar y exponer las "fallas y los enfoques dominantes sobre el medio ambiente favorecidos por las autoridades 
corporativa, estatales e internacionales" como diría Robbins (2004: 12). Busca también ser una semilla que siembra un pensamiento alternativo, una política distinta y opciones de cambio en la relación sociedadnaturaleza, en especial nuevos modelos de desarrollo (Blaikie 1995; Robbins 2004). Fortaleciendo esta idea, Martínez-Alier (2004) dirá respecto a la EP, que es un movimiento para cambiar el mundo. El mismo autor menciona en otro escrito que "los diferentes actores de los conflictos ecológicos distributivos, con sus diferentes dotaciones de derecho y poder, ponen en duda y desafían las reivindicaciones de otros apelando a distintos lenguajes de valoración dentro de su amplio repertorio cultural" (Martínez-Alier 2011b: 320). Es una herramienta que analiza "los procesos de significación, valorización y apropiación de la naturaleza que no se resuelven, ni por la vía de la valoración económica de la naturaleza ni por la asignación de normas ecológicas a la economía" (Ibid 2011b: 2). Pretende generar espacios de reapropiación de la naturaleza, la ecología y la cultura, a través de procesos que se van a diferenciar de valores mercantiles que pretenden homologar y apropiarse del significado de la naturaleza (Lipietz 2002; Martínez-Alier 2011b).

La importancia de la EP recae también en sus características como proyecto que nace desde lo académico (pero que debe superar este espacio) y se nutre de lo práctico, permitiendo estudiar las relaciones que existen entre las desigualdades de poder y la degradación de la naturaleza, a través de relaciones altamente politizadas, tanto discursiva como materialmente (Batterbury 2015; Blaikie 2014; Bustos et al. 2015), que van dando forma a los conflictos socio-ambientales que intentan equiparar el poder que tienen otros actores. Para la EP el poder es parte esencial de los conflictos socio-ambientales, lo que para MartínezAlier (2011b) significará la capacidad que se tiene para imponer una decisión sobre otros, y su vez, de imponer a todas las partes implicadas en un conflicto socio-ambiental, una valoración única del lenguaje.

El desarrollo de la EP ha permitido contribuir a una vasta extensión conceptual, teórica y empírica, ocupándose de la excesiva invisibilización de las relaciones de poder en el acceso a los bienes naturales, la producción discursiva y material de la naturaleza, invitando a cuestionar la naturalización de la crisis ambiental, por lo que pondrá fuerte énfasis en politizar las relaciones entre la sociedad civil y la naturaleza (Bustos et al. 2015; Lipietz 2002; Robbins 2004). Se ha transformado en una de las respuestas contra la crisis ambiental actual, producto de la industrialización y la modernidad, añadiendo a la naturaleza como un fenómeno que en su esencia es altamente político (Bustos et al. 2015). La EP entiende los conflictos socio-ambientales como prácticas concretas sobre los ecosistemas, esto quiere decir, sobre la forma en que se produce el conocimiento, tanto el sentido como el significado que adquiere para los actores inmersos en los ecosistemas en conflicto (Bustos et al. 2015; Durand et al. 2012), los cuales serán clave en la toma de decisiones y la cooperación entre estos para la superación de este estado (Blaikie 2014).

Más aún, junto con sus virtudes la ecología política ha sido también desafiada, por su coherencia interna, métodos o coherencia programática. Para Neumann (2005), por ejemplo, la EP tiene bastantes obstáculos que debería observar desde la amplitud teórica, conceptual y metodológica, como los enfoques no del todo definidos. El poder ocupa una posición central en la revisión de la EP, sin embargo, otro desafío de la EP es generar dimensiones que lo aborden con mayor complejidad para comprender las relaciones asimétricas existentes entre la sociedad y naturaleza (Bustos, Prieto y Barton 2015). Destacan en esta campaña la multiplicidad de textos que integran los aportes de Foucault sobre el discurso, con la noción de poder y la lectura política ecológica (ejemplos: Rattu and Véron 2016; Valdivia 2015).

En el caso de Latinoamerica, la EP está particularmente marcada por la modernidad y colonialidad. Los procesos de conquista e integración subordinada al sistema internacional han sido claves para comprender la construcción de las relaciones y significaciones entre las sociedades establecidas y la naturaleza (Alimonda 2011a; Bustos et al. 2015). Más aún, los diversos gobiernos y sus economías emergentes sustentan la promoción e intensificación de la presión exportadora de bienes naturales y patrones de consumo crecientes, provocando el aumento de la pobreza y desigualdad (Piketty 2014).

La ecología política latinoamérica (EPLat) ha cumplido un rol central problematizando este proceso de modernización y sus impactos ambientales, especialmente estudiando y sistematizando por más de tres décadas conflictos socio-ambientales en la región. En el siguiente apartado se exploran la multiplicidad de temas que la EPLat presenta en la región buscando aportar con una sistematización los temas que la EP ha abordado en la región. De modo paralelo, se exploran claves de análisis que aporten al estudio interdisciplinar de los conflictos ambientales, por ejemplo, el rol de lo comunicacional en el estudio político ecológico de los conflictos socio-ambientales. 


\section{Problemas y conflictos socio-ambientales que aborda la EP Latinoamérica}

Las definiciones entregada sobre problemas y conflictos socio-ambientales presentan el desafío de ser amplias, pudiendo abarcar un sinfín de temas. Tras estudiar diversas fuentes e investigaciones sobre conflictos socio-ambientales bajo una mirada política-ecológica (basados en textos que expresamente declaraban esa afiliación teórica), se desarrolló un análisis temático que permitiera sistematizar qué ha observado la ecología política latinoamericana. Como resultado del análisis temático se presenta la preeminencia de diez temas centrales y múltiple temáticas emergentes en la ecología política latinoamericana.

Una primera temática central en la EPLat ha resultado ser el análisis económico crítico. Desde la comodificación de la naturaleza, la apropiación y transformación de bienes públicos en privados, y el extractivismo, que abarca desde la minería, actividad forestal, agropecuaria y pesquera. La naturaleza no puede existir sin una fuente biofísica que la alimente, y la ecología política se ha preocupado de exponer los efectos que ha provocado la separación entre la sociedad y la naturaleza, mediada por raciocinios y métodos propios de la economía, por dar una categoría amplia. En lo particular, la EPLat se ocupa del posicionamiento que ha tenido la economía por sobre lo social y su excesiva energía por ejercer una valoración mercantil de los bienes comunes (Aguilera Klink and Alcantara 1994; Leff 2003), bajo el entendimiento que la sociedad ha tenido una co-evolución con la naturaleza en un campo con diversos lenguajes (Martínez-Alier 2011b). Frente a esta co-evolución, producto de una vasta generación de conocimientos por medio del diálogo, tensión e interacción, es que los conflictos socio-ambientales por medio de su organización y cohesión buscan producir proyectos alternativos de sociedad (Leff 2003). El rol de la colonización y globalización han sido también abordado y estudiado desde esta perspectiva por la EP (Escobar 2006 2011; Machado Aráoz 2011). La vertiente más amplia de este discurso desde la EP la ocupan los estudios extractivistas, donde se exponen los mecanismos políticos-económicos que permiten la extracción de bienes naturales a tazas por sobre su capacidad de renovación o recuperación, o bien, produciendo una serie de efectos negativos sobre el ecosistema o sociedad (Alimonda 2011b; e.g. DelgadoRamo 2010; Delgado-Ramo and Diego Correa 2013; Giraldo 2015). Como expone Durand et al. (2012: 12) dentro de la EP la definición de los mecanismos mediante los cuales se da el control y manejo de los bines naturales ha ocupado un lugar especial.

En relación con el manejo de los bienes y servicios naturales, estudios y discusiones en torno a temas de poder, gobernanza y mecanismos institucionales abarcan un segundo tópico de especial interés para la EPLat. Esto, dado que los conflictos socio-ambientales suelen discutir respecto al ejercicio y distribución del poder en la toma de decisiones sobre la naturaleza (Alimonda 2011b; Blaikie 2014). Según Baikie (2014), esta tendencia podría ser contrarrestada por mecanismos donde la sociedad civil tenga el derecho a ser incluida en la toma de decisiones. El manejo de los bienes y distribución del poder se ejemplifica en los conflictos sucedidos en Bolivia durante el 2003 con la denominada guerra del gas y guerra del agua.

Tanto para las élites de Bolivia como para los indígenas en las áreas de los valles, el gas significaba la base financiera de los futuros proyectos territoriales, los cuales el Estado al impulsar su privatización por empresas extranjeras, generaron tensiones y movilizaciones por su control (Perreault 2013). A su vez, se produce la denominada guerra del agua iniciada en Cochabamba como resultado contra la privatización de los servicios de agua potable y alcantarillado a cargo de concesiones trasnacionales. En ambos conflictos la EP se manifiesta en la capacidad de control o no que tiene el Estado, la sociedad civil o las empresas sobre los bienes naturales bolivianos como también lo es la valoración mercantil de los bienes comunes (Andrade 2011; Hinojosa et al. 2015).

El excesivo posicionamiento de lo económico respecto al manejo de los bienes naturales, ha conllevado a cuestionar los procesos de significación, intentos de valorización y apropiación sobre la naturaleza por parte de la ciudadanía (Leff 2003). Así, un tercer aspecto importante a considerar de la ecología política latinoamericana, son los sistemas de valores y sustentabilidad que presiden los actores participes en los conflictos socio-ambientales. La cultura entrega las bases teóricas para (re)orientar y (re)significar por medio de prácticas culturales y ecológicas la relación de la sociedad con la naturaleza (Martínez-Alier 2011b). Estas prácticas forman un sistema de redes el cual resulta relevante de observar y señalar sus características ya que pueden generar proyectos alternativos de sociedad y su relación con la naturaleza y su significado (Leff 2003). En este sentido, el conflicto socio-ambiental en el Perú asociado a la extracción minera y de hidrocarburos clarifica el poco o nulo control de las comunidades por sobre la élite local en la significación de la naturaleza, conflicto que además se agudizó tras el descubrimiento de yacimiento de gas a fines del siglo XX (Bebbington 2009; Andrade 2011). 
La explotación de hidrocarburos en Perú ha tenido altos costos especialmente para las comunidades indígenas. Un 72\% de la Amazonía peruana se encuentra alrededor de proyectos de hidrocarburos (Andrade 2011), afectando a más de 34 comunidades indígenas de la zona de los ríos Tigres y Corrientes quienes además de los efectos a la naturaleza, han tenido repercusiones en su salud. El Ministerio de Salud demostró que 98\% de los menores sobrepasa los límites aceptables de cadmio en la sangre (Bebbington 2007; Andrade 2011). Por lo que el posicionamiento de lo económico por sobre significados sustentables de las comunidades indígenas, ha permeado en la decisión de un Estado que ha tenido que negociar y redistribuir territorios en lotes de hidrocarburos, zonas naturales protegidas, reservas indígenas, zonas urbanas, forestales, y otros mecanismos (Gamboa 2009).

Como una cuarta temática asociada al significado de la naturaleza, la EPLat ha dedicado parte de sus escritos al reconocimiento del lado político, ético, social y cultural de la naturaleza. La naturaleza y lo ecológico no son espacios externos a lo social, pero tampoco son espacios dependientes pero separados. Desde la EP -y en Latinoamérica se ha estresado esta idea-, el medio ambiente es un ambiente politizado, que es "percibido e interpretado a partir de diferentes puntos de vista, los cuales reflejan las experiencias y los valores culturales de los diferentes actores, comunidades, instituciones y sociedades en cuestión" (Durand et al. 2012: 12). Desde esta concepción, el medo ambiente no sólo es un espacio con características sociales, sino que es un espacio social en sí mismo, donde otras luchas sociales se entretejen y desarrollan. Los movimientos sociales, luchas y procesos de emancipación han encontrado en la EP una voz y un espacio desde el cual exponer sus problemas y conflictos, pero también desde donde construir alternativas. Se refuerza acá la ideas de la EP no sólo como el hacha y las semillas (Escobar 2011; Loftus 2009; Robbins 2004), sino como algo que también se ejerce: "Is something that people do, a research effort to expose the forces at work in ecological struggle and document livelihood alternatives on the face of change" (Robbins 2004: 13).

Otros tópicos que se relacionan con las luchas sociales presentes en Latinoamérica y forman una quinta temática general, se debaten en el terreno de la epistemología política. Intenta definir algún tipo de racionalidad ecológica que incorpore como eje vertical palabras con nuevos significados y sentidos políticos para constituirse como motor de movilización para grandes mayorías de la población (Leff 2001).

Los conflictos socio-ambientales representan aquellas disputas de poder que emergen de intereses y estrategias, por el derecho a la apropiación y aprovechamiento de los diversos bienes naturales (Blaikie 2014; Leff 2003; Lipietz 2002; Loftus 2009). Como anteriormente se señaló, no se limita solamente a impactos ecológicos y derechos ambientales, sino que se extienden a la disputa por el significado de la naturaleza, buscando un nuevo trato y defensa de los derechos de las poblaciones locales y nacionales por su autonomía, que les permita auto-gestionar sus territorios y culturas (Ibíd: 27-28).

En relación a lo anterior, la justicia ambiental presenta una sexta temática que desde la ecología política ha sido abordada de manera asociativa a otras temáticas, por ejemplo, con conflictos económicos, derechos civiles, reconocimiento, participación, justicia climática, decrecimiento económico socialmente sostenible, economía ecológica, y ecologismo de los pobres (Leff 2003; Martínez-Alier 2008; Navarro 2005). Sin embargo, y en un sentido más amplio, buena parte de los escritos por la ecología política latinoamericana conciernen a temas de justicias ambientales o relativas (e.g. Bonilla Elvira 2015; Montserrat 2011; Palacio 2006; Walter 2014).

En la presente discusión sobre la apropiación y gestión de la naturaleza, la temática de la conservación (séptima) ha ido tomando fuerza dentro de la EP en los últimos años (Palacio 2006). La conservación desde la EP presenta con fuerza ideas asociadas a la multiplicidad territorial (e.g. PortoGonçalves 2015) y la apropiación territorial (o territorialización) de un espacio vía mecanismo de dominación y control. Lo anterior, relevando el rol que el Estado y otros mecanismo institucionales tienen para dar valor un a un espacio distinto al valor que el mercado le daría, valorando el servicio ambiental o la relación del territorio con la población (Calderón-Contreras 2013; Leff 2003; Robbins 2004; Trentini 2012). La conservación se ha relacionado también, desde la EP en general, pero aún en desarrollo en Latinoamérica, con temas de la expansión de lo urbano, pero también del rol o re-valoración de los espacios naturales dentro de la urbanidad (Delgado-Ramo 2015a; Domene Gómez 2006; Lukas and Fragkou 2014; March and Ribera-Fumaz 2014).

Otra mirada a la conservación la dan los escritos y movimientos existentes en Latinoamérica que discuten los derechos constitucionales de la naturaleza, generando una octava temática la EPLat. Un ejemplo se encuentra en cómo la EP ha sistematizado en Ecuador cómo el aumento de conflictos socioambientales provocados por la explotación y contaminación de petróleo (Fountaine et al. 2007; Gudynas 
2009), generada por las empresas petroleras ubicadas mayoritariamente en la región Amazónica, las que han realizado más de 991 derrames entre 1994-2001, generado que relación de las comunidades con las empresas petroleras sea de desconfianza y enfrentamientos (Fountaine 2004; Fountaine et al. 2007; Bebbington 2009). En esta línea, las organizaciones étnicas de la Amazonía adoptaron acciones colectivas de negociación y confrontación. Otras, por interpelar al Estado y detener las lógicas de mercado, institucionalizando sus movimientos luego de las reformas constitucionales ambientales de 1997-1998 (Andrade 2011; Fountaine et al. 2007). Fenómeno que sitúa a la EPLat como espacio esencial para la conformación de una red institucional de cuidado a la naturaleza.

La EP es un campo en construcción y en el mundo ha comenzado a abordar una diversidad de temas que, de a poco, comienzan a ser abordados también desde Latinoamérica. Una novena temática, la degradación y contaminación ambiental, se ha comenzado a tematizar en la región, muchas a veces asociada al tema del riesgo que suponen para la población (e.g Cruz and Brazán 2006; Martínez and Hernández 2009; Romero et al. 2010; Toledo 1996). Esto ha sido el caso de Chile. Durante la dictadura chilena en los 80 se realizaron diversas reformas en la zona austral del país, transformando las dinámicas territoriales de Chiloé. En especial, sectores de Estado y empresarios (nacionales y extranjeros) decidieron potenciar la zona como polo de desarrollo de la industria salmonera para competir en el mercado internacional (Berdegué et al. 2012; Claude y Oporto 2000; Moncada 2016). Previo a ello, el uso de los bienes naturales se centraba en actividades como la agricultura y pesca artesanal, pero tras la llegada de la acuacultura de salmón, la población rural comenzó a trabajar mayoritariamente en torno a ella, desarrollando infraestructura y servicios, como nuevos caminos o establecimientos de una red de electricidad (Claude y Oporto 2000). En 2007 el ecosistema del archipiélago de Chiloé se vio fuertemente afectado por el virus ISA el cual contaminó a los salmones produciendo el colapso temporal de la industria internacional (Berdegué et al. 2012; Claude y Oporto 2000; Moncada 2016). Tras la degradación y contaminación ambiental en Chiloé, periódicamente han ocurrido diversas manifestaciones por los daños provocados por la industria del salmón.

También en relación a la temática del riesgo, se encontró que un décimo tema que la EP ha comenzado a abordar refiere a los desastres socio-naturales, tanto en otras latitudes (e.g. Aboagye 2012; Blaikie 1996; Collins 2008; Wisner et al. 2003) como en la región (e.g. Da Cruz 2003; Leff 2003; Romero Toledo y Romero Aravena 2015). Respecto al calentamiento y cambio climático global es un tema de preocupación de la EP desde hace bastante tiempo (Birkenholtz 2012; Blaikie 1995; Martinez-Alier 2004), sin embargo no ha permeado aún con la fuerza que se podría espera en los estudios desde o sobre Latinoamérica. Por lo tanto, no logra definir en sí mismo un tema de la EPLat.

Otras temáticas, pero aún incipientes en la región, incluyen la EP que trata temas urbanos (e.g. Gabriel 2014; Lawhon et al. 2014; Njeru 2006; Mougeot 2005; Swyngedouw and Heynen 2003; Zimmerer and Bassett 2003), sobre la escases de recursos, y no sólo agua, también petróleo y hasta fósforo, por nombrar casos innovadores (e.g. Cordell and White 2011; Le Billon and Cervantes 2009; Le Billon 2001; Loftus 2009). Argentina presenta un caso de conflicto socio-ambiental que combina lo urbano y escases de agua. En la ciudad de La Elena la urbanización se intensificó en los últimos 20 años, provocando movilizaciones en la población por el acceso al agua potable. A raíz de ello, se creó durante enero 2010 una nueva Comisión Barrial demandando a las autoridades provisión de agua. En 2012 participaron de la Banca XXI del Consejo Deliberante de Tandil, y a su vez, un Diputado Provincial presentó un recurso de protección solicitando el acceso al agua potable (Guerrero et al. 2015; Merlinsky 2013). En este sentido, la distribución desigual de poder junto a la intensificación de la urbanización, provocó instancias de nuevos mecanismos de poder para contrarrestar aquello.

La EP ha abordado además una serie de otras temáticas poco frecuentes aún en Latinoamérica. Por ejemplo, se ha abordado la temática de la conservación de la biodiversidad, desde lo los genético hasta la diversidad de las especies (Maris 2012). También temas tecnológicos, como la basura digital y de tecnología o narrativas digitales sobre lo natural (e.g. Bennett 2010; Lawhon and Murphy 2012; Pickren 2014b, 2014a). El turismo es otra temática, que por el rol que esa actividad tiene en Latinoamérica, se puede esperar sea mayormente abordado por la EPLat, añadiendo temáticas desde el ecoturismo hasta el impacto o rol del turismo en la conservación (e.g Bonilla Priego et al. 2011; Cole 2014; Dahlberg et al. 2010). En una perspectiva actualizada a la crisis migratoria que se vive en Medio Oriente, Europa y África, hay casos desde la EP abordando la temática (Bettini and Andersson 2014; Morrissey 2012), la cual por los movimientos demográficos de Latinoamérica, también abre un nuevo espectro de investigación desde la EP. 
De modo transversal a los temas recién listados, la mayoría de los textos estudiados prestaban especial atención a los procesos comunicacionales de los conflictos socio-ambientales que exponían. Lo anterior por el rol que cumple la comunicación para los actores o grupos en conflicto, principalmente para dar a conocer sus demandas y el problema en cuestión, pero también porque logran ver en que esa comunicación cumple un rol de comunicar e informar pero también transformador. Busca generar cambios. Se observa en esta tendencia que junto con el poder, lo comunicacional es un tema central de la EPLat. Sin duda lo anterior no es algo único de la EP, y varios otros autores que abordan el tema ambiental, como Anthony Giddens (2009), John Hannigan (1995) y Ulrich Beck (1999), por nombrar algunos, dan cuenta de la importancia de la comunicación en lo ambiental y el considerar los procesos comunicativos en el estudio y abordajes de los conflictos socio-ambientales.

En simple y pecando de la imprecisión que lo sintético presupone, lo comunicacional para los autores mencionados, al igual que para Habermas, no es un mecanismo pasivo de transmisión de información, sino que lo comunicacional es una acción en sí misma, toda vez que sustenta la forma en que las personas actúan, los proceso suceden y las instituciones modernas operan. Toda acción está sustentada en el pensamiento, un racionamiento basado en símbolos que se comunican interna y externamente. Ese proceso racional lejos de ser uno sólo, único y estéril en cada persona, está formado evolutivamente y se asocia una cultura, contexto y sociedad especifica (Habermas 1999). Es un proceso de entendimiento cooperativo de interpretación que tiene por finalidad obtener definiciones de cualquier situación que puedan ser reconocidas intersubjetivamente por los sujetos (Ibíd. 103-104), así como por los movimientos sociales, que parecen seguir la misma empresa en relación a los conflictos socio-ambientales, según se consta en la ecología política latinoamericana.

La exploración de los temas tratados por la EPLat permitió además observar que tras la crítica o develamiento de múltiples conflictos, hay también presente una crítica a la modernidad o los modos de vida de la sociedad occidental moderna. De este modo, tenemos que la EP reconoce la relevancia de lo comunicacional para la comprensión de los conflictos socio-ambientales, proceso mediante el cual se logra además develar condiciones propias de nuestra sociedad moderna. El entendimiento de lo comunicacional, en este sentido, vendría a ser el medio para la comprensión de las condiciones y racionalidades que están a la base de la formación de los conflictos socio-ambientales en nuestra sociedad. Pero, ¿cómo lograr este proceso? ¿Cómo logramos estudiar lo comunicacional de los conflictos y vincular ese entendimiento con la crítica a la modernidad?

Tras la exploración de múltiples teorías, encontramos que la teorización de la acción comunicativa propuesta por Habermas entrega claves de análisis importantes de ser consideradas. Por ejemplo, Habermas plantea que una teoría o entendimiento de la racionalidad a la base de lo social, debe ir de la mano del entendimiento y teoría de la sociedad, y la única forma de comprender una sociedad como la moderna, es mediante una teoría de la acción comunicativa (Habermas 1999: 20-25). Esta teoría de la acción comunicativa (AC), ha de permitir pensar la racionalidad que hay detrás de la sociedad moderna y la forma que toman los modos de vida actuales. Esta racionalidad, a su vez, es la misma que sustenta las acciones y condiciones sociales que permiten y enmarcan las acciones que se etiquetan como conflictivas con la naturaleza, las cuales son objeto de estudio de la EP. Leer qué elementos de la Teoría de la Acción Comunicativa puede aportar a los estudios de la EP, es una empresa que se sustenta en conocer qué hay detrás de los conflictos socio-ambientales, más allá de sus causas contextuales y su develación. Más aún, y como se explicará en mayor detalle a continuación, una EP sustentada en develar las acciones instrumentales, sin comprender la AC de los conflictos, no logra develar la totalidad de las condiciones que posibilitan a ese conflicto "ser."

\section{Teoría de la acción comunicativa y la ecología política}

En este apartado y siguiendo la línea de pensamiento presentado, se exploran elementos de la TAC que pueden contribuir al estudio de los conflictos socio-ambientales, especialmente en el entendimiento reflexivo de qué significa lo comunicacional en estos conflictos en relación a los procesos de modernización y la sociedad moderna. En lo concreto, se observa que las nociones de AC, acción instrumental (AI) y la colonización del mundo de la vida por el sistema, son tres elementos que resaltan en esta teoría. Un entendimiento acabado de cada una de estas dimensiones está más allá de las posibilidades que el presente artículo permite, pero a continuación se presentan algunas claves de lectura relevantes y cómo estos conceptos han sido usados en esta investigación asociados a la EP. 
A modo general, se debe comprender que Habermas pretende aportar al entendimiento de los sistemas sociales modernos, entregando claves de lectura para entender la diferenciación que éstos sufrieron con la disolución de las sociedades tradicionales. Lo anterior, mediante el avenimiento de una racionalidad comunicativa, y la emergencia de la sociedad capitalista que nace con la modernidad, tanto en el nivel económico como institucional (Giddens 1999; Habermas 1999). Aporta así al estudio de los conflictos socio-ambientales, contextualizándolos históricamente en el proceso de racionalización de la sociedad moderna y su complejización. Permite explicar los temas que aquejan a la racionalidad en la realidad social actual, añadiendo la dimensión comunicativa como parte esencial de esta teoría de la sociedad en la modernidad (Habermas 1999; Lepe Carrión 2009).

En este contexto, la AC representa la interacción mediada por símbolos y acciones que definen comportamientos comprendidos y validados por normas morales de los sujetos participes en un campo de relaciones específico, por medio de normas consensuales, expectativas reciprocas y comunicación lingüística basada en la intersubjetividad de los sujetos (Habermas 1999). La AI, en contraste, implica condiciones empíricas, en las que se refleja la expansión de las fuerzas productivas del sistema económico y la colonización del mundo de la vida, regidas por reglas técnicas (Lepe Carrión 2009).

Respecto a la colonización del mundo de la vida, en las sociedades tradicionales distintos procesos, mundos o sectores de la sociedad estaban unidos: la ciencia, la moral, las leyes y lo artístico, estaban integrados y eran parte del sistema político-religioso, que también estaban integrados (Habermas 1985, 1999; Robles 2012). La ciencia, lo moral y el arte estaban dominados por la religión y las iglesias (en su sentido más amplio), las cuales a su vez eran parte de los estados feudales o grupos de poder. En Habermas, se explica el proceso de conformación y desarrollo de la sociedad moderna como aquel en donde estos sectores comenzaron a diferenciarse. Por un lado, el sistema político-estado con el religioso, pero por otro, cada sector (el de las leyes, lo artístico, la ciencia, etcétera) también se comienzan a diferenciar, a tener sus propias normas, actores y acciones (Fernández 1997; Habermas 1984, 1999). Es la racionalidad del mundo moderno, producto del desarrollo de la ilustración y posteriormente de las revoluciones industriales y políticas, la que ha generado un proceso de diferenciación progresiva de y entre estas esferas sociales. Para Habermas este proceso de separación se enmarca en una dinámica aún mayor: el desacoplamiento del sistema con el mundo de la vida (Habermas 1999; Robles 2012).

El sistema es para la TAC la forma de control tecnificado que asegura y coordina las acciones de los sujetos, bajo reglas que operan de manera funcional a las tareas y actividades que cada uno desarrolla. Paralelamente, el mundo de la vida es un espacio interior de los sujetos, que aglutina las diferentes formas que estos interpretan el mundo (Lepe Carrión 2009). El desacoplamiento entre ambos genera descoordinación entre estos sectores de la sociedad, por ejemplo, entre la ciencia, técnica y moral. Sin embargo, esa separación nunca es total, el sistema sigue enraizado y existe en su relación con el mundo de la vida, espacio que a su vez se encuentra colonizado y guiado por la racionalidad del sistema.

Para la EP este proceso debe ser observado cuidadosamente, ya que desde él se observa que la relación técnica y mediada de la sociedad moderna con la naturaleza, con claras fronteras entre la ciencia natural, las leyes que median esa relación y aprensiones morales que le suceden, no son universales, sino que son productos de un desarrollo particular de la sociedad, de una evolución que, en palabras del mismo Habermas, está aún en proceso. Es decir, los conflictos socio-ambientales de hoy se sustenta en una racionalidad y forma de sociedad que no siempre ha sido y, según diversos autores, está cambiando, ya cambió o definitivamente nunca logro sus pretensiones originales de evolución (e.g. Latour 2007; Luhmann 1998).

Esta comprensión de la modernidad puede ser fundamental para la EP en el entendimiento que el advenimiento de conflictos socio-ambientales son propios de nuestra modernidad y no de las sociedades tradicionales. Con lo anterior no se está defendiendo a priori el mito que las sociedades pre-modernas vivían en armonía con su entorno, pero si se reconoce que los conflictos socio-ambientales de hoy tienen particularidades no vistas antes, y una escala temporal y espacial de afectación mucho mayor (Beck 1999; Bell 2012; Hannigan 2006). La evolución de las sociedades ha transformado la racionalización de los sujetos, y simultáneamente los sistemas sociales se han complejizado, variando constantemente las manifestaciones comunicativas de los sujetos, como también los significados en el mundo de la vida que han sido colonizados. Por tanto, suceden diversos modos de argumentación, así como nuevas posibilidades de la acción comunicativa bajo escenarios que son reflexivos en los procesos de racionalización de los sujetos (Habermas 1999). 
En este sentido, la TAC es significativa para el estudio de los conflictos socio-ambientales, ya que presenta una dimisión de totalidad y, simultáneamente, la (re)construcción de las diferentes interpretaciones y significados que han dado sentido al mundo pero se han visto mermadas por las contradicciones que presenta el sistema social actual (Habermas 1999; Lepe Carrión 2009). En lo práctico, la generación de una AI por parte de los sujetos provoca simultáneamente una AC acorde con la racionalidad del mundo moderno, esto quiere decir y acorde a la esencia de la modernidad, sucede distanciamiento y disputa por el significado o interpretación de la naturaleza. Por esto, es que la AC podría ser esencial para los conflictos socio-ambientales de la actualidad, no sólo por su contexto histórico sino que por elementos significativos que la componen. Permitiría en gran medida descomplejizar los conflictos socio-ambientales: En un primer momento entrega ciertos suministros que identifican aquellos elementos que estos buscan disolver de la racionalidad moderna imperante en su relación y participación sobre la naturaleza; pero por sobre todo, la AC permite generar en los conflictos socio-ambientales la capacidad de potenciar los proyectos alternativos de sociedad que estos pretenden alcanzar. Para lograrlo se presenta como clave la conformación de redes que están en constante diálogo generando conocimiento, para de esta forma, asegurar un mundo de la vida cohesionado y un horizonte societal representativo.

A través de la racionalización del mundo de la vida es que el capitalismo ha logrado su expansión en el primer mundo, y luego a través del todo el orbe, integrando las esferas políticas y económicas, pero que su vez se ha visto debilitado y objetivado, afectando a los contextos de diálogos que están orientados por la AC (Habermas 1999, Vol. II). En este sentido, es necesario para efectos de esta investigación, tener presente la dimensión económica y política de las sociedades modernas, y que son recurrentemente mencionadas en los escritos de la EP como se ha revisado. En concreto el surgimiento del dinero como medio simbólico, como se mencionó anteriormente, se asocia al proceso de evolución de las sociedades modernas que trae consigo una mayor complejización de las diferentes esferas sociales, la cual ha significado para los sujetos en la sociedad (re)pensar las estructuras simbólicas de su mundo de la vida y alcanzar nuevos acuerdos comunicativos, los cuales deben generarse a través de nuevos procesos de racionalidad que posibiliten hacer de este mundo, un mundo reconocible y compartido entre todos (Habermas 1999).

Una de las características que ha generado el capitalismo en las sociedades modernas ha sido la interacción y potenciamiento mutuo, a través de los subsistemas como lo denominaba Habermas, del dinero y el poder por medio de la institución estatal (Ibíd: 452). El Estado y la economía al ser parte esencial del sistema, logran penetrar en las esferas de la vida privada como lo es el de la opinión pública, o la sociedad civil. Su núcleo lo conforman redes comunicativas, que por medio de la institución estatal se potencian utilizando herramientas como la prensa y medios de comunicación de masas -que en la actualidad se representan por el internet, televisión y radio, mayoritariamente -, generando mecanismos de reproducción y participación de la sociedad civil, que tarde o temprano, permiten la obtención de legitimación de estas esferas (Ibíd: 452).

Para Habermas (1999) estos mecanismos presentes en la sociedad se encuentran estructurados comunicativamente y crean la necesidad de distinguir el intercambio que se produce tanto en el mundo de la vida como en el sistema. La interacción del Estado y de la economía producida en el mundo de la vida, provocan procesos de intercambio específicos, como lo son los bienes y servicios, salario y trabajo, como también decisiones políticas (Ibíd: 453), (re)definiendo las relaciones y roles que cada actor social cumplirá. En otras palabras, en el mundo moderno las personas actúan diferenciadamente y sus relaciones están medidas instrumentalmente, evitando así que tengan un entendimiento global del resto de los procesos sociales. Esto último, será de vital importancia para comprender la complejización de la sociedad moderna y los conflictos socio-ambientales.

En este sentido, la definición de los roles que cumplen los sujetos en la sociedad genera procesos de abstracción y la colonización mundo de la vida por el sistema, etapa posterior al de desacoplamiento antes descrito (Fernández 1997). Esto conlleva que el proceso de estudio de los conflictos socio-ambientales debe entender que toda manifestación de la ciudadanía va a ser diferenciada y abstraída a cada sub-sistema en vez de ser entendida como una demanda global. Lo legal a lo legal y lo económico a ser resuelto por lo económico, reduciendo así la capacidad de un entendimiento global e integrado de las problemáticas. Esta diferenciación si bien tiende a la integración social y el entendimiento intersubjetivo (la comunicación en cada sistema altamente regulado hace más expedita dada la estructura que forma la cultura, la sociedadorganizaciones y la personalidad), reduce las posibilidades de integración sistémica o las acciones estratégicas orientadas al éxito de una acción social, más integrada a cambios a nivel del sistema (Habermas 
1984; Robles 2012). Resulta necesario hacer mención a la noción de diferenciación funcional entre sistemas parcialmente diferenciados entregada por Luhmann (1998), la cual si bien ha de aportar a este análisis, hace difícil integrarla a la lectura de la EP por su negación de la existencia de los sujetos y la acción.

En consecuencia, el paso de sociedades tradicionales al de sociedades modernas generó el proceso de monetarización y burocratización de la vida social de los sujetos, lo que desencadenó la destrucción de formas tradicionales de la vida social (Habermas 1999), permitiendo nuevas formas de organización y efectividad para perdurar y reproducir las tareas materiales del mundo de la vida en la forma de producción del sistema capitalista industrial (Ibíd: 455). Estas nuevas formas de reproducción a lo largo del proceso de modernización ha complejizado cada una de las esferas sociales, produciendo la proliferación de nuevos actores que no se restringen solamente a un ámbito de la sociedad, sino que permean en cada esfera de lo social. Respecto los conflictos socio-ambientales, la actuación del Estado y la sociedad civil en la relación con la naturaleza cobra especial relevancia en la distribución del poder en la toma de decisiones sobre el medio ambiente (Alimonda 2011b; Blaikie 2014).

Esta redefinición monetaria tanto de la forma de vida político-cultural como del mundo privado de los sujetos, provoca un rediseño de las "metas, relaciones y servicios, y de las estructuras simbólicas del mundo de la vida mediante la burocratización de decisiones, de deberes y derechos, de responsabilidades y dependencias" (Habermas 1999). La monetarización y burocratización producen efectos colaterales no sólo en el mundo de la vida y su reproducción material, sino que provocan severos daños en el sistema y la reproducción simbólica, y a su vez, en la AC que realizan los actores sociales, ya que comienza a funcionar la instrumentalización del mundo de la vida en sí (Ibíd: 458). A medida que el sistema económico impone sus reglas en otras esferas de la sociedad, "el consumismo y el individualismo posesivo y las motivaciones relacionadas con el rendimiento y la competitividad adquieren una fuerza configuradora" (Ibíd: 461).

Como resultado, la complejización y abstracción de la sociedad moderna ha generado en la cotidianeidad de los sujetos, prácticas comunicativas mediadas por procesos de racionalidad unilateral, y producción de formas de vidas centradas en un utilitarismo en torno a la especialización (Ibíd: 458-461). Estas prácticas son a su vez esenciales en la expansión de las fuerzas productivas del sistema económico capitalista, y posteriormente del neoliberalismo, lo que construye un escenario ideal de la AI en la colonización del mundo de la vida.

Este contexto, la EPLat identifica un campo de relaciones que se encuentra en disputa por la (re)apropiación del significado de la naturaleza y la dificultad del acceso y control de los bienes naturales. Busca posicionar y (re)orientar las prácticas culturales-ecológicas, presentando proyectos alternativos que involucren por medio de la participación vinculante y democratización, a los actores sociales que se resisten a que naturaleza sea homologada a valores económicos. Los conflictos socio-ambientales buscan la producción de proyectos societarios alternativos al que ha presentado la modernidad, generando un sinfín de conocimientos sobre las interpretaciones de la naturaleza, a través de una racionalidad (o varias) que centre al ambientalismo en las estrategias discursivas y simbólicas de los sujetos, que posibilite la transformación de las relaciones desiguales de poder existentes en la actualidad.

\section{Reflexiones y conclusiones}

La TAC de Habermas permite retomar la noción de totalidad al análisis social, económico y político, y posicionar, por un lado, el rol que ha tenido la ciencia a lo largo del proceso constitutivo en la vida cotidiana de los sujetos, y por otro, lo comunicacional dentro de la complejidad ambiental actual. Este proceso de reflexión que nos invita la TAC, posiciona lo comunicacional como un factor importante en la construcción y evolución de la racionalidad moderna, la cual ha generado subjetividades de dominio en los sujetos sobre la naturaleza, buscando legitimarse a través de diferentes mecanismos de poder, en el que la ciencia por medio de sus técnicas de instrumentalización de la razón (Habermas 1984, 1985) ha sido participe de la crisis ambiental que vivimos hoy como sociedad.

A través de esta investigación, hemos podido identificar algunos elementos de la TAC como de la EP que nos permitirían intentar descomplejizar el estudio de los conflictos socio-ambientales en la actualidad. El proceso que se realiza desde la TAC en la complejidad ambiental y en los conflictos socioambientales, abre un escenario de reflexión que la EP debería considerar como constitutivo de ella. Y desde Latinoamérica, nos lleva a plantearnos que si de verdad se pretende superar los problemas socioambientales, es urgente y necesario considerar las bases que han permitido la construcción de la sociedad moderna actual. 
La EP si bien debe continuar su lucha por develar los problemas emanados de la distribución desigual y de las estrategias de apropiación de los recursos ecológicos (Leff 2003), debe por sobretodo, tener la capacidad de ser un campo multidisciplinario el cual genere procesos reflexivos de cómo superar los problemas de la modernidad o la modernidad misma, ya que sus objetos de estudio son constitutivos de la realidad moderna. Si la EP continúa identificando por separado problemas, no va a lograr un impacto real en la superación de los mismos. No basta con a identificar un conflicto socio-ambiental, es necesario además considerar sus causas asociadas a la modernidad, permitiendo asociar el abordaje de los problemas con el potenciar proyectos alternativos de sociedad.

Nos surgen muchas incertidumbres y preguntas sobre el futuro de la EP a nivel global como desde estas latitudes, si ¿realmente los proyectos alternativos de sociedad van a lograr ser visibilizados? o ¿cómo se construyen, entendiendo las dificultades que se pueden enfrentar?, o bien ¿'será posible superar los problemas ecológicos sin poder superar la racionalidad moderna? A partir de estas reflexiones y la invitación que realiza la TAC a la EP de poder entender que los problemas socio-ambientales y la crisis ecológica de la actualidad como constitutivos de los enunciados de la modernidad, es que podemos dar un salto cuantitativo y cualitativo en cuanto a la profundización y complejización de los estudios de la EP en las diferentes áreas antes descritas. Desde un plano académico como también y por sobre todo, desde el mundo social, ya que entiende lo comunicativo como un proceso socio-histórico en los campos de relaciones desiguales en Latinoamérica, los cuales generan significados sobre la naturaleza.

Concluyendo, el traspaso de la sociedad tradicional a la sociedad del capitalismo avanzado generó una abstracción en las diferentes esferas sociales, logrando nuevas formas de vida y relaciones de intercambio que tuvieron y han tenido efectos que se continúan profundizando hasta el día de hoy. En estas trasformaciones se han visto mermadas y trasformadas la esfera de la vida privada y de la opinión pública, generando un sistema económico que presenta en gran medida medios de dinero y altas cuotas de poder; y a su vez, un sistema administrativo o estatal, que presenta mayoritariamente medios de poder y altas cuotas de dinero, producto de la evolución de las sociedades y del mayor posicionamiento que ha tenido el mercado en todo el orbe producto del modelo neoliberal, contribuyendo a su complejización.

En este sentido, los conflictos socio-ambientales hoy por hoy estarían configurados por la evolución de las relaciones de intercambio que ha vivido el capitalismo a través del proceso de monetarización y burocratización del mundo de vida, modificando las relaciones y metas que los sujetos presentan. Ahora bien, el campo en el cual se desenvuelven los conflictos socio-ambientales, se sustenta principalmente desde una epistemología política (Leff 2001) que se enfrenta constantemente a formas de mercantilización de la naturaleza, de manera que estos pretenden equiparar la toma de decisiones que se tiene sobre la naturaleza (Alimonda 2011b; Blaikie 2014).

Las manifestaciones comunicativas de los conflictos socio-ambientales en la mercantilización del mundo de la vida, permiten generar códigos a través de medios simbólicos bajo escenarios reflexivos, que no sólo buscan la diferencia de lo que se quiere transmitir o comunicar y/o generar acciones estratégicas, sino que pretenden descomplejizar los procesos de racionalización de los conflictos socio-ambientales (Habermas 1999). Esta capacidad reflexiva provee mecanismos más simples de comunicación, tanto para la sociedad en sí como para los sujetos al interior de estos, buscando recomponer las relaciones de poder y el mundo de la vida de los sujetos en conflicto, por tanto, de los proyectos alternativos de sociedad. Lo anterior se ha vertido en Latinoamérica en un trabajo académico que ha pensado algunas temáticas y conflictos socio-ambientales en mayor profundidad, como los presentados en el primer apartado del presente escrito, más aún y como se ha mencionado, la EP ha encontrado en la región una serie de espacios de difusión y discusión de éstas y otras temáticas, como lo son blogs, páginas webs, grupos y movimientos ciudadanos y espacios organizados como congresos y seminarios. Queda abierta así la necesidad de nuevas investigaciones que exploren y describan esta otra veta de la EP, en la cual las propuestas de proyectos alternativos, como los que invita la TAC, parecen tomar cuerpo y comenzar a desarrollarse a una velocidad mayor que la capacidad que tiene el mundo académico de reflejarlo. Son, al parecer, en estas empresas comunicativas alternas donde la EP ha encontrado en Latinoamérica su mayor potencial.

De estos modos, a través de la TAC y la EP, se busca la descomplejización o superación de la racionalidad moderna, generando mecanismo o las bases que permitan (re)orientar la imagen racionalizada del mundo, y encaminar a la humanidad hacia una autorreflexión y realización plena (Lepe Carrión 2009). Buscan promover prácticas y significados para la (re)apropiación de la naturaleza y la cultura, conformando redes que produzcan y (re)produzcan conocimiento en la interacción y dialogo entre un mismo grupo u otros (Leff 2003), cuestión que dependerá de muchos factores, pero principalmente de la AC de los sujetos 
en la conformación de las imágenes del mundo ante un proyecto societario alternativo, que tenga como horizonte, confeccionar un mundo cohesionado y que asegure identidad (Habermas 2002) y representatividad.

\section{Referencias}

Aboagye, D. 2012. The political ecology of environmental hazards in Accra, Ghana. Journal of Environment and Earth Science 2(10): 157-172.

Aguilera, F. and V. Alcantara. 1994. De la economía ambiental a la economía ecológica. Barcelona and Madrid: Icaria, FUHEM.

Alimonda, H. 2011a. La colonialidad de la naturaleza. Una aproximación a la Ecología Política Latinoamericana. In Alimonda, H. (ed.). La naturaleza colonizada: ecología política y minería en América Latina. Buenos Aires: CLACSO. Pp. 21-60.

Alimonda, H. (ed.). 2011b. La naturaleza colonizada: ecología política y minería en América Latina. Buenos Aires: CLACSO : Ediciones CICCUS.

Alonso, A. and V. Costa. 2002. Por uma sociologia dos conflitos ambientais no Brasil. In Alimonda, H. (ed.). Ecología política. naturaleza, sociedad y utopía. Buenos Aires: CLACSO. Pp. 115-135.

Azuela, A. and P. Mussetta. 2009. Algo más que el ambiente. Conflictos sociales en tres áreas naturales protegidas de México. Revista de Ciencias Sociales 1(16): 191-216.

Andrade, K. 2011. Gobernanza ambiental en Bolivia. Gobernanza en tres dimensiones: de los recursos naturales, la conservación en áreas protegidas y los pueblos indígenas. FLACSO: Ecuador.

Barca, S. 2015. Trabajo y cambio climático?` Qué espacio hay para la investigación en ecología política? Ecología política (50): 26-30. Academia

Bardwell, LV. 1991. Problem-framing: a perspective on environmental problem-solving. Environmental Management 15(5): 603-612. Academia

Batterbury, S.P.J. 2004. Cultural and political ecology at the AAG century: application and impact in the world. Cultural and Political Ecology Newsletter. (archived)

Batterbury, S.P.J. 2015. Doing political ecology inside and outside the academy. In Bryant R. (ed.). International handbook of political ecology. Cheltenham, UK: Edward Elgar. Pp. 27-43.

Bebbington, A.J. 2007. La sostenibilidad social de los recursos rurales: apreciaciones a partir de los conflictos mineros en latinoamérica. Debate Agrario 42: 31-78.

Bebbington, A.J. 2009. The new extraction? Rewriting the political ecology of the Andes. NACLA Report on the Americas 42(5): 12-20.

Beck, U. 1999. World risk society. Malden, MA: Polity Press.

Bell, M. 2012. An invitation to environmental sociology. 4th ed. Thousand Oaks, California: Pine Forge Press.

Bennett, J. 2010. Vibrant matter a political ecology of things. Durham: Duke University Press.

Berdegué J., A.J. Bebbington, J. Escobal, A. Favareto, I. Fernández, P. Ospina, H. Munk Ravnborg, F. Aguirre, M. Chiriboga, I. Gómez, L. Gómez, F. Modrego, S. Paulson, E. Ramírez, A. Schejtman and C. Trivelli. 2012. Territorios en movimiento. dinámicas territoriales rurales en América Latina. Santiago de Chile: Centro Latinoamericano para el Desarrollo Rural.

Berger, P.L. and T. Luckmann. 1990. The social construction of reality: a treatise in the sociology of knowledge. New York: Anchor Books.

Bettini, G. and E. Andersson. 2014. Sand waves and human tides: exploring environmental myths on desertification and climate-induced migration. The Journal of Environment and Development 23(1): 160-185. Researchgate

Birkenholtz, T. 2012. Network political ecology: method and theory in climate change vulnerability and adaptation research. Progress in Human Geography 36(3): 295-315.

Blaikie, P.M. 1995. Changing environments or changing views? A political ecology for developing countries. Geography 80(3): 203-214.

Blaikie, P.M. 2014. Towards an engaged political ecology. In: Brun, C. and M. Jones (eds.). Alternative development: unravelling marginalization, voicing change. Farnham: Ashgate. 
Blaikie, P.M., T. Cannon, I. Davis and B. Wisner. 1996. Vulnerabilidad: el entorno social, político y económico de los desastres. Santafé de Bogotá: Tercer Mundo Editores.

Bonilla Elvira, I. 2015. La feminización de la justicia ambiental desde la ecología política. Una alternativa para Ocotlán, Jalisco. Revista Latino-Americana de Geografia e Gênero 6(2): 38-51.

Bonilla Priego, M.J., J.J. Najera and X. Font. 2011. Environmental management decision-making in certified hotels. Journal of Sustainable Tourism 19(3): 361-381.

Bordehore, C. 2001. Problemas ambientales, problemas humanos. Aledo, A. and J.A. Domínguez (eds.). Sociología ambiental. Granada: Grupo Editorial Universitario. Pp. 321-355.

Botero, P. 2010. Arturo Escobar y sus fuentes críticas en la construcción de pensamiento latinoamericano. Revista Latinoamericana en Ciencias Sociales, Niñez y Juventud 8(1): 151-173.

Bourdieu, P. 2007. El sentido práctico. Buenos Aires: Siglo Veintiuno.

Bourdieu, P. 2011. Las estrategias de la reproducción social. Buenos Aires: Siglo Veintuno.

Bustos, B., M. Prieto and J. Barton (eds.). 2015. Ecología política en Chile: naturaleza, propiedad, conocimiento y poder. Santiago de Chile: Ed. Universitaria.

Calderón-Contreras, R. 2013. Ecología política: hacia un mejor entendimiento de los problemas socioterritoriales. Economía, sociedad y territorio 13(42): 561-569.

Campos, F. and J. Larenas. 2012. La despolitización del conflicto socio-ecológico en la legislación medioambiental chilena a partir de los años noventa. Revista Bitácora Urbano Territorial 21(2): 45-56.

Claude, M. and J. Oporto. 2000. La ineficiencia de la salmonicultura en Chile: aspectos sociales, económicos y ambientales. Santiago: Terram.

Cole, S. 2014. Tourism and water: from stakeholders to rights holders, and what tourism businesses need to do. Journal of Sustainable Tourism 22(1): 89-106.

Collins, TW. 2008. The political ecology of hazard vulnerability: Marginalization, facilitation and the production of differential risk to urban wildfires in Arizona's White Mountains. Journal of Political Ecology 15(1): 21-43.

Cordell, D. and S. White. 2011. Peak Phosphorus: clarifying the key issues of a vigorous debate about longterm Phosphorus security. Sustainability 3(12): 2027-2049.

Cruz, E.G. and J.C.L. Brazán. 2006. Prensa chilena y ecología política en el Chile democrático. La miopía de la contaminación ambiental. Revista Enfoques: Ciencia Política y Administración Pública IV(5): 113-130.

Da Cruz, J. 2003. Ecología social de los desastres. Montevideo: Ediciones Coscoroba.

Dahlberg, A., R. Rohde and K. Sandell. 2010. National parks and environmental justice: comparing access rights and ideological legacies in three countries. Conservation and Society 8(3): 209-224.

Delgado-Ramo, G.C. (ed.). 2010. Ecología política de la minería en América Latina. Mexico: Universidad Nacional Autónoma de México.

Delgado-Ramo, G.C. 2015a. Cambio climático y la ecología política urbana del agua. Southern Papers Series/Working Papers \#16. Buenos Aires: CLACSO.

Delgado-Ramo, G.C. 2015b. Complejidad e interdisciplina en las nuevas perspectivas socioecológicas: la ecología política del metabolismo urbano. Letras Verdes. Revista Latinoamericana de Estudios Socioambientales 17: 108-130.

Delgado-Ramo, G.C. and L.R. Diego Correa (eds.). 2013. Ecología política del extractivismo en América Latina: casos de resistencia y justicia socioambiental. Buenos Aires: CLACSO.

Durand, L., F. Figueroa and M. Guzmán (eds.). 2012. La naturaleza en contexto: hacia una ecología política Mexicana. Mexico, D.F: Universidad Nacional Autónoma de México.

Domene Gómez, E. 2006. La ecología política urbana: una disciplina emergente para el análisis del cambio socioambiental en entornos ciudadanos. Documents d'Anàlisi Geogràfica 48: 167-178.

Escobar, A. 2006. An ecology of difference: equality and conflict in a glocalized world. Focaal 47: 120137. related

Escobar, A. 2011. Ecología política de la globalidad y la diferencia. in Alimonda, H. (ed.). La naturaleza colonizada: ecología política y minería en América Latina. Buenos Aires: CLACSO. Pp. 61-91.

Estévez, R.A., C.B. Anderson, J.C. Pizarro, and M.A. Burgman 2015. Clarifying values, risk perceptions, and attitudes to resolve or avoid social conflicts in invasive species management: confronting invasive species conflicts. Conservation Biology 29(1): 19-30. Academia 
Fernández, S. 1997. Habermas y la teoría crítica de la sociedad. Cinta de Moebio 1: 27-41.

Fountaine, G. 2004. Microconflictos ambientales y crisis de gobernabilidad en la Amazonía ecuatoriana. Iconos 21: 35-46.

Fountaine, G., G. Vlie and R. Pasquis. 2007. Políticas ambientales y gobernabilidad en America Latina. FLACSO: Ecuador.

Gabriel, N. 2014. Urban political ecology: environmental imaginary, governance, and the non-human. Geography Compass 8(1): 38-48.

Galtung, J. 1996. Peace by peaceful means: peace and conflict, development and civilization. Thousand Oaks, CA: Sage. Exerpts

Gamboa, C. 2009. Informe Amazonía, hidrocarburos y pueblos indígenas: un estado de la cuestión en el caso peruano (2003-2008). DAR: Lima.

Gerring, J. 2007. Case study research: principles and practices. New York: Cambridge University Press.

Giddens, A. 1995. La constitución de la sociedad: bases para la teoría de la estructuración. Buenos Aires: Amorrortu.

Giddens, A. 1999. Consecuencias de la modernidad. Madrid: Alianza Editorial.

Giddens, A. 2009. The politics of climate change. Cambridge: Polity.

Giraldo, O.F. 2015. Agroextractivismo y acaparamiento de tierras en América Latina: una lectura desde la ecología política. Revista Mexicana De Sociología 77(4): 637-662.

Gudynas, E. 2009. La ecología política del giro biocéntrico en la nueva Constitución de Ecuador. Revista de estudios sociales (32): 34-47.

Guerrero, E., L. Wagner, C. Rodríguez and B. Sosa. 2015. Acciones colectivas y recursos naturales en conflicto. Historia ambiental de luchas urbanas por agua y sierras en Tandil, Argentina. Revista Luna Azul 41: 274-295.

Harvey, D. 2012. Rebel cities: from the right to the city to the urban revolution. London: Verso.

Hinojosa, L. A.J. Bebbington, G. Cortez, J. Chumacero, D. Humphreys and K. Hennermann. 2015. Gas y desarrollo: dinámica territorial rural en Tarija, Bolivia. Serie documento de trabajo 172. Programa Cohesión Territorial para el Desarrollo. Santiago: Rimisp.

Habermas, J. 1984. Ciencia y técnica como "ideología." Madrid: Tecnos.

Habermas, J. 1985. El discurso filosófico de la modernidad (Der philosophische diskurs der moderne: zwölf vorlesungen). 1. Aufl. Frankfurt am Main: Suhrkamp.

Habermas, J. 1999. Teoría de la acción comunicativa (Vol. I \& II). Madrid: Taurus Humanidades.

Hannigan, J.A. 1995. Environmental sociology: a social constructionist perspective. London; Routledge.

Hannigan, J.A. 2006. Environmental sociology. 2nd ed. London: Routledge.

Homer-Dixon, T.F. 1994. Environmental scarcities and violent conflict: evidence from cases. International Security 19(1): 5-40.

Krüger, F. (ed.). 2015. Cultures and disasters: understanding cultural framings in disaster risk reduction. London: Routledge.

Latour, B. 1997. On actor network theory: a few clarifications plus more than a few complications. [en línea]. Disponible en http://www.f.waseda.jp/sidoli/Latour_ANT_Clarifications.pdf

Latour, B. 2007. Nunca fuimos modernos: ensayo de antropología simétrica. Buenos Aires: Siglo Veintiuno Editores.

Lawhon, M. and J.T. Murphy. 2012. Socio-technical regimes and sustainability transitions: insights from political ecology. Progress in Human Geography 36(3): 354-378.

Lawhon, M., H. Ernstson and J. Silver. 2014. Provincializing urban political ecology: towards a situated UPE through African urbanism. Antipode 46(2): 497-516. Academia

Le Billon, P. 2001. The political ecology of war: natural resources and armed conflicts. Political Geography 20(5): 561-584.

Le Billon, P. and A. Cervantes. 2009. Oil prices, scarcity, and geographies of war. Annals of the Association of American Geographers 99(5): 836-844.

Leff, E. 2001. Los derechos del ser colectivo y la reapropiación social de la naturaleza: a guisa de prólogo. In Leff, E. (ed.) Justicia ambiental: construcción y defensa de los nuevos derechos ambientales culturales y colectivos en América Latina. México, D.F: PNUMA/UNAM. Pp. 7-34. 
Leff, E. 2003. La ecología política en América Latina: un campo en construcción. Sociedade e Estado 18(1/2): 17-40.

Leff, E. 2007. La complejidad ambiental. Polis 16.

Leff, E. 2010. El desvanecimiento del sujeto y la reinvención de las identidades colectivas en la era de la complejidad ambiental. Polis 27.

Lepe Carrión, P. 2009. Síntesis interpretativa de la obra: la teoría crítica de la sociedad de Habermas: la crisis de la sociedad industrializada. Revista Digital Cuaderno de Materiales.

Lipietz, A. 2002. ¿Qué es la ecología política?: la gran transformación del siglo XXI. Santiago: LOM.

Loftus, A. 2009. Rethinking political ecologies of water. Third World Quarterly 30(5): 953-968.

Luhmann, N. 1998. Complejidad y modernidad: de la unidad a la diferencia. Madrid: Trotta.

Lukas, M. and M.C. Fragkou. 2014. Conflictividad en construcción: desarrollo urbano especulativo y gestión de agua en Santiago de Chile. Ecología Política 47: 67-72.

Machado Aráoz, H. 2011. El auge de la minería transnacional en América Latina. De la ecología política del neoliberalismo a la anatomía política del colonialismo. In Alimonda, H. (ed.). La naturaleza colonizada: ecología política y minería en América Latina. Buenos Aires: CLACSO. Pp. 135-180.

March, H. and Ribera-Fumaz, R. 2014. Una revisión crítica desde la Ecología Política Urbana del concepto Smart City en el Estado español. Ecología Política. 47: 29-36.

Maris, V. 2012. De la naturaleza a los servicios ecosistémicos. Una mercantilización de la biodiversidad. Ecología Política 44: 27-32.

Martínez, P. and Hernández, E. 2009. Impactos de la contaminación del Río Santiago en el bienestar de los habitantes de El Salto, Jalisco. Espacio Abierto 18(4): 709-729.

Martinez-Alier, J. 2004. Ecological distribution conflicts and indicators of sustainability. International Journal of Political Economy 34(1): 13-30.

Martínez-Alier, J. 2008. Conflictos ecológicos y justicia ambiental. Papeles de relaciones ecosociales y cambio global 103: 11-28.

Martínez-Alier, J. 2011a. Ecología humana y economía política. In F. Aguilera Klink and V. Alcantara (eds.), De la economía ambiental a la economía ecológica. Barcelona and Madrid: Icaria, FUHEM.

Martínez-Alier, J. 2011b. El ecologismo de los pobres: conflictos ambientales y lenguajes de valoración. Antrazyt, Barcelona: Icaria.

Mattelart, A. and M. Mattelart. 1997. Historia de las teorías de la comunicación. Buenos Aires: Paidós.

Merlinsky, G. 2013. Cartografías del conflicto ambiental en Argentina. Argentina: Ediciones CICCUS.

Moncada, E. 2016. El archipiélago de Chiloé y los contornos inciertos de su futuro: colonialidad y saqueo extractivista. Chile: Centro de Estudios Sociales de Chiloé.

Montserrat M.M. 2011. Conflictos socioambientales de la acuicultura del camarón Centroamérica: Un análisis desde la justicia ambiental. Ecología Política 41: 90-96. Researchgate

Morrissey, J. 2012. Rethinking the'debate on environmental refugees': from'maximilists and minimalists' to'proponents and critics'. Journal of Political Ecology 19: 36-49.

Mougeot, L.J.A. 2005. Agropolis: the social, political, and environmental dimensions of urban agriculture. London, Ottawa: International Development Research Centre; Earthscan.

Navarro, J.V. 2005. La globalización del ecologismo; del ecocentrismo a la justicia ambiental. Medio Ambiente y Comportamiento Humano 6(2): 183-204.

Neumann, R.P. 2005. Chapter 1. In Making political ecology. London: Hodder Arnold.

Njeru, J. 2006. The urban political ecology of plastic bag waste problem in Nairobi, Kenya. Geoforum 37(6): 1046-1058.

Oberschall, A. 1978. Theories of social conflict. Annual Review of Sociology 4(1): 291-315.

Palacio, G. 2006. Breve guía de introducción a la ecología politica (Ecopetrol): orígenes, inspiradores, aportes y temas de actualidad. Gestión y Ambiente 9(3): 143-156.

Parsons, T. 1968. La estructura de la acción social. Salamanca: Ed. Guadarrama.

Perrault, T. 2007. De la guerra del agua a la guerra del gas: gobernabilidad de recursos, neoliberalismo y protesta popular en Bolivia. In S. Spronk and C. Crespo (eds.). Depsués de las guerras del agua en Bolivia. La Paz: Plural Editores.

Pickren G. 2014a. Geographies of E-waste: towards a political ecology approach to e-waste and digital technologies. Geography Compass 8(2): 111-124. 
Pickren, G. 2014b. Political ecologies of electronic waste: uncertainty and legitimacy in the governance of e-waste geographies. Environment and Planning A 46(1): 26-45.

Pikketty, T. 2014. Capital in the Twenty-First century. Cambridge: Belknap Press.

Porto-Gonçalves, CW. 2015. Amazônia enquanto acumulação desigual de tempos: Uma contribuição para a ecologia política da região. Revista Crítica de Ciências Sociais (107): 63-90.

Rattu, P. and R. Véron. 2016. Towards a Foucauldian urban political ecology of water: rethinking the hydrosocial cycle and scholars' critical engagement. Foucault Studies: 21: 138-158.

Robbins, P. 2004. Political ecology: a critical introduction. Oxford: Blackwell.

Robles, F. 2012. Epistemologías de la modernidad: entre el etnocentrismo, el racionalismo universalista y las alternativas latinoamericanas. Cinta de Moebio 45: 169-203.

Romero, H., C. Fuentes and P. Smith. 2010. Ecología política de los riesgos naturales y de la contaminación ambiental en Santiago de Chile. Scripta Nova: Revista Electrónica de Geografía y Ciencias Sociales XIV(331): 52.

Romero Toledo, H. and H. Romero Aravena. 2015. Ecología política de los desastres: vulnerabilidad, exclusión socio-territorial y erupciones volcánicas en la patagonia chilena. Magallania (Punta Arenas) 43(3): 7-26.

Rubington, E. and M.S. Weinberg. 2003. The study of social problems: seven perspectives. New York: Oxford University Press.

Swyngedouw, E. and N.C. Heynen. 2003. Urban political ecology, justice and the politics of scale. Antipode 35(5): 898-918.

Toledo, V. 1996. Latinoamérica: crisis de civilización y ecología política. Gaceta Ecológica 38.

Trentini, F. 2012. Ecología política y conservación: el caso del "co-manejo" del parque nacional Huapi y el pueblo mapuche. Revista Pilquen XIV(15): 1-15.

Ungar, P. and S. Roger. 2005. Complejidad: una reflexión dese la ciencia de la conservación. Nómadas 22: 36-46.

Valdivia. G. 2015. Eco-governmentality. In Perreault, T., G. Bridge and J. McCarthy (eds.) the routledge handbook of political ecology. London: Routledge. Pp.

Walter, M. 2009. Conflictos ambientales, socioambientales, ecológico distributivos, de contenido ambiental... Reflexionando sobre enfoques y definiciones. Boletín Ecos 6: 1-9.

Walter, M. 2014. Political ecology of mining conflicts in Latin America: an analysis of environmental justice movements and struggles over scales. PhD thesis. Barcelona: Universitat Autònoma de Barcelona.

Wisner, B., P.M. Blaikie, T. Cannon and I. Davis. 2003. At risk: natural hazards, people's vulnerability and disasters. London : Routledge. 3 chapters

Yin, R.K. 2009. Case study research: design and methods. Thousand Oaks, CA: Sage.

Zimmerer, KS. and T.J. Bassett (eds.). 2003. Political ecology: an integrative approach to geography and environment-development studies. New York: Guilford Press. 